\title{
Case Report \\ Femtosecond Laser Refractive Surgery after Descemet Stripping-Automated Endothelial Keratoplasty
}

\author{
Simon Sheung Man Fung, Alfonso Iovieno, Vijay Shanmuganathan, and Vicenzo Maurino
}

Cornee and External Diseases Service, Moorfields Eye Hospital NHS Trust, London, 162 City Road, London EC1V 2PD, UK

Correspondence should be addressed to Simon Sheung Man Fung, simon.fung@moorfields.nhs.uk

Received 28 November 2011; Accepted 19 January 2012

Academic Editors: A. Ferreras and R. Khandekar

Copyright (C) 2012 Simon Sheung Man Fung et al. This is an open access article distributed under the Creative Commons Attribution License, which permits unrestricted use, distribution, and reproduction in any medium, provided the original work is properly cited.

Purpose. To report the use of femtosecond laser-assisted in situ keratomileusis (LASIK) in the treatment of hyperopia subsequent to Descemet stripping-automated endothelial keratoplasty (DSAEK). Methods. Interventional case report. Results. A 66-year-old woman with Fuchs endothelial dystrophy developed bullous keratopathy after cataract surgery in her right eye. She underwent DSAEK with a significant postoperative hyperopic shift in her refraction. Thirteen months after DSAEK, she underwent wavefrontguided, femtosecond laser-assisted LASIK (IntraLase, Inc., Irvine, CA/AMO, Inc., IL, USA). Pretreatment unaided visual acuity was $20 / 120$, and best-corrected visual acuity was $20 / 20$ with a refraction of $+3.25 /-0.50 \times 170$. One year after laser refractive correction, unaided visual acuity was $20 / 20$ with a refraction of $+0.25 /-0.75 \times 160$. Conclusion. To our knowledge, this is the first paper on the successful treatment of hyperopic shift related to DSAEK with wavefront-guided, femtosecond laser-assisted LASIK.

\section{Introduction}

Descemet stripping-automated endothelial keratoplasty (DSAEK) is the surgical procedure of choice for corneal endo thelial diseases, allowing the surgeon to selectively replace the diseased host endothelium [1].

The advantages of DSAEK over traditional penetrating keratoplasty $(\mathrm{PK})$ include rapid visual rehabilitation, minimal-induced astigmatism maintenance of structural integrity, and predictable postoperative corneal power [2].

The additional tissue layer in the posterior corneal surface could affect the optical characteristics postoperatively. Studies have reported significant hyperopic shift after DSAEK surgery [2]. This change is believed to be caused by the additional thickness and/or the meniscal shape of the lamellar graft inserted [3].

Refractive surgery has been used in patients who underwent PK for correcting postoperative ametropia [4]. Femtosecond thin-flap LASIK has been shown to safely and effectively reduce postoperative refractive error, in particular the spherical component, in patients who have previously undergone PK [5].
We hereby report the first case of treatment of hyperopia after DSAEK with wavefront-guided, femtosecond laser-assisted LASIK (IntraLASIK).

\section{Case Presentation}

A 66-year-old woman was referred to the corneal service at Moorfields Eye Hospital with intermittent blurring of vision, and a diagnosis of bilateral Fuchs endothelial dystrophy was made. She subsequently developed visually significant cataracts in her right eye and decided to undergo cataract surgery. Uncorrected visual acuity (UCVA) was 20/60 OD and 20/30 OS, with best-corrected visual acuity (BCVA) being 20/40 OD with a refraction of $+1.50 /+0.50 \times 145$ and $20 / 30$ OS with a refraction of $-0.25 /+1.00 \times 80$.

Uncomplicated right phacoemulsification with implantation of a single-piece posterior chamber intraocular lens (IOL, Akreos Adapt, Bausch and Lomb UK, Ltd. Surrey, England) was performed, aiming for emmetropia. Postoperatively, examination of the right eye showed persistent bullous keratopathy, with UCVA of 20/120 and BCVA of 20/60, 
from day 1 to 4 months poststatus. Intraocular pressure was not raised during this period. Anterior chamber, vitreous, optic nerve, and retina were within normal limits.

4 months after cataract surgery, the patient underwent uncomplicated DSAEK with corneal lamellar graft prepared with a 350-micron plate Moria microkeratome (Moria, Antony, France) and a $8.25 \mathrm{~mm}$ trephine punch. After Descemet membrane stripping, the lamellar graft was inserted with the assistance of a Busin glide (Moria, Antony, France).

4 months after DSAEK, the UCVA was 20/120 OD and BCVA was $20 / 20$ with a refraction of $+3.25 /-0.50 \times 170$. Lefteye refraction remained unchanged. Slit-lamp examination showed clear cornea with DSAEK graft in good position. Patient was given a trial of soft contact lens but was intolerant and became increasingly symptomatic of anisometropia. After the alternatives for hypermetropic correction were discussed, wavefront-guided femtosecond laser-assisted LASIK was performed, 13 months after DSAEK.

The following steps were applied in the surgical procedure. The laser treatment was conducted under topical anaesthesia. Femtosecond laser (IntraLase Inc., Irvine, CA, USA) was used to create a $9.0 \mathrm{~mm}$ superiorlyhinged anterior lamellar flap at 110 microns. The flap was lifted and a customized wavefront (CustomVue, AMO Inc., IL, USA) ablation was performed with the S4IR (AMO Inc., IL, USA) in a $8.7 \mathrm{~mm}$ zone at a depth of $36 \mu \mathrm{m}$. The flap was then replaced, and the interface was irrigated. A bandage contact lens was subsequently inserted after the flap was adhered (Figure 1).

The patient was treated with topical levofloxacin $5 \mathrm{mg} / \mathrm{mL}$ and a tapering dose of dexamethasone $0.1 \%$ over 4 weeks. A punctal plug was also inserted due to dry eye symptoms. Seven months later, the patient had UCVA of 20/20 with a refraction of $+0.25 /-0.75 \times 160$ and remained unchanged at 1 year after procedure. Endothelial cell count at the last followup was 1684 cells $/ \mathrm{mm}^{2}$. Figure 2 shows the topographic readings before and after refractive correction.

\section{Discussion}

To our knowledge, this is the first paper on the application of wavefront-guided femtosecond laser-assisted LASIK for hyperopic correction in post-DSAEK patients.

Pseudophakic bullous keratopathy is one of the commonest indications for corneal grafting. DSAEK is gaining in popularity due to its advantages over PK. However, postoperative hyperopic shift is common after DSAEK [2]. If cataract surgery was to be performed concurrently with DSAEK, the IOL power could be adjusted to compensate for the hyperopic shift [3].

After DSAEK, postoperative correction with spectacles or contact lenses is often helpful but could be problematic in patients who are intolerant or those with difficulty in contact lens insertion. Other treatment modalities such as IOL exchange or sulcus piggyback IOL insertion are possible, but the risks of endothelial cell loss and corneal graft rejection with intraocular surgery render them unfavorable.

Laser refractive surgery has been used to treat postoperative ametropia in patients who underwent PK. Both

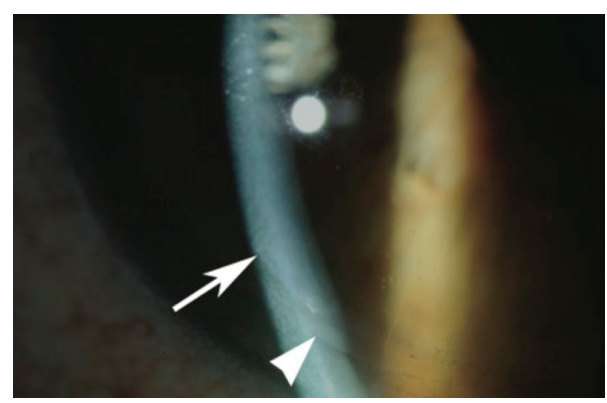

Figure 1: Postoperative appearance of femtosecond laser-assisted LASIK on a patient with DSAEK. The LASIK flap (arrow) and the DSAEK layer (arrowhead) are highlighted.

microkeratome- and femtosecond laser-assisted LASIK have been shown to be effective in the correction of post-PK ametropia, particularly the spherical component [5]. Importantly, no significant changes to endothelial cell density could be demonstrated in post-PK patients who underwent microkeratome-LASIK [6].

Levinger et al. first reported the use of femtosecond laserassisted arcuate keratectomy in a post-DSAEK patient for correcting postoperative astigmatism [7]. No complications were observed 7 months after procedure. A recent case series by Ratanasit and Gorovoy studied the use of microkeratomeLASIK and PRK in 5 patients with previous DSAEK, achieving good refractive outcomes without any graft rejections or the need of enhancement surgery [8].

In our case, the patient underwent femtosecond laserassisted LASIK 13 months after DSAEK. No complications, including graft failure, graft rejection, refractive instability, and corneal ectasia, were observed up to 1 year post-operatively. Femtosecond laser-assisted LASIK has the adventage over microkeratome LASIK of producing more predictable and uniform flap thickness, a more astigmatically neutral flap and less intraoperative epithelial injury, as shown by previous studies [9]. The effect of femtosecond laser-assisted LASIK on the corneal endothelium has also been studied in human subjects. No significant changes to endothelium cell density or hexagonality have been shown up to 1 year after laser procedure [10]. The endothelial cell count in our patient remained healthy and comparable to Ratanasit and Gorovoy's study.

In summary, this paper suggests that femtosecond laserassisted LASIK can be safely and effectively used in the correction of ametropia in post-DSAEK patients. Further investigations into the long-term effects of this technique are needed.

\section{Fthical Approval}

Informed consent was obtained from the patient prior to the submission of this paper and the accompanying images. 

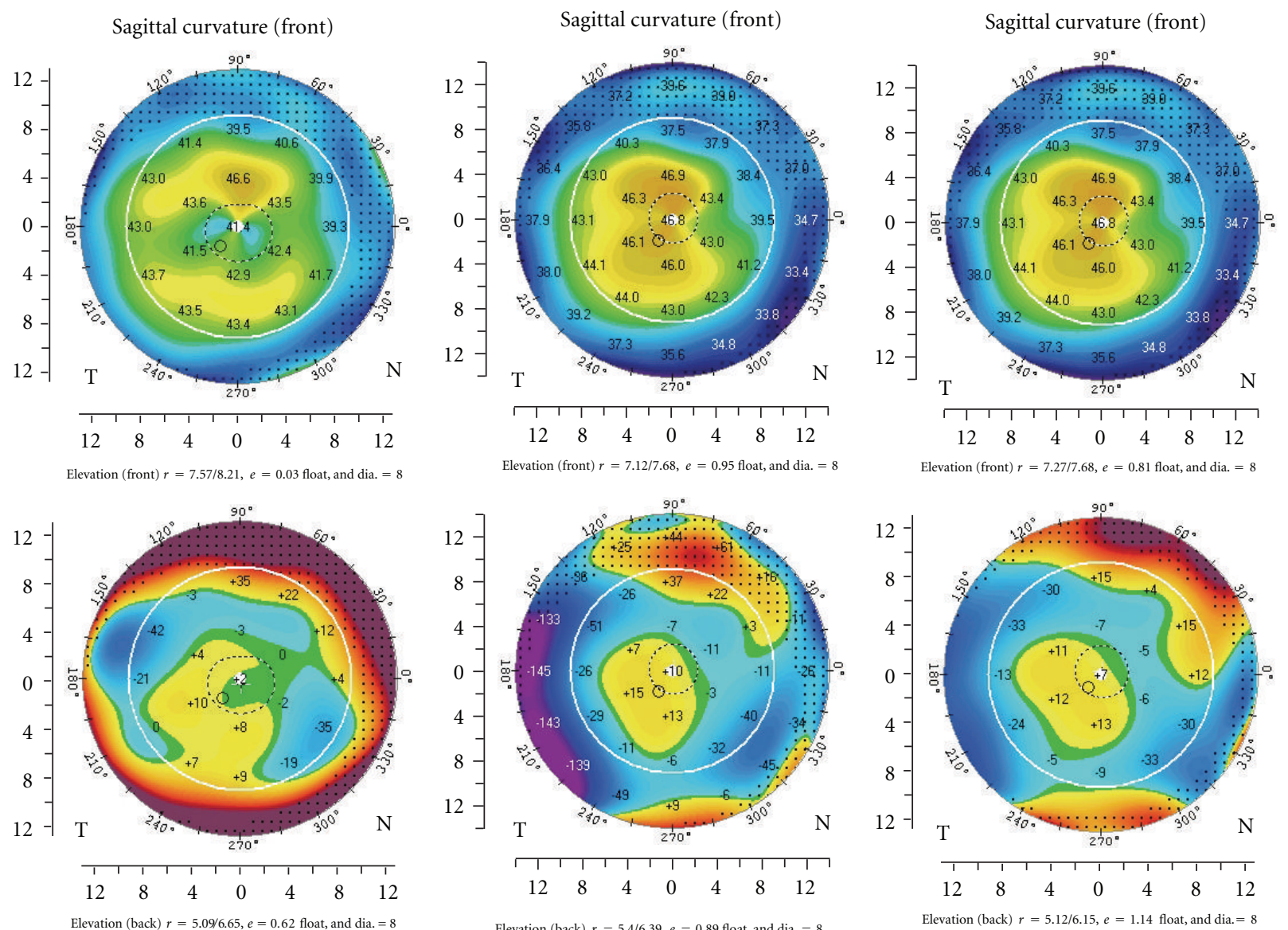

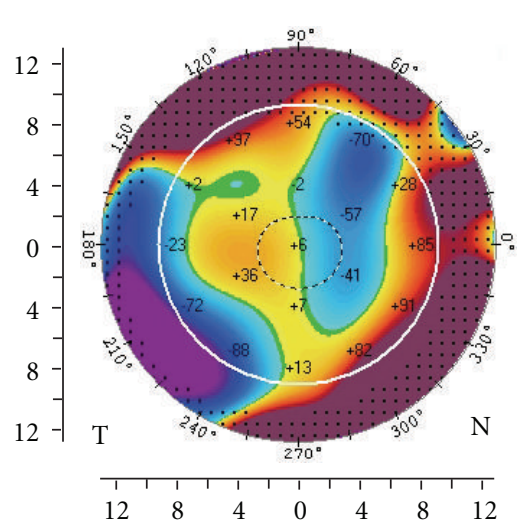

(a)

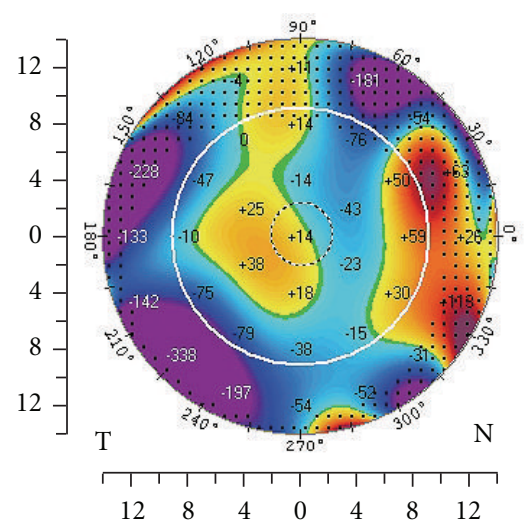

(b)

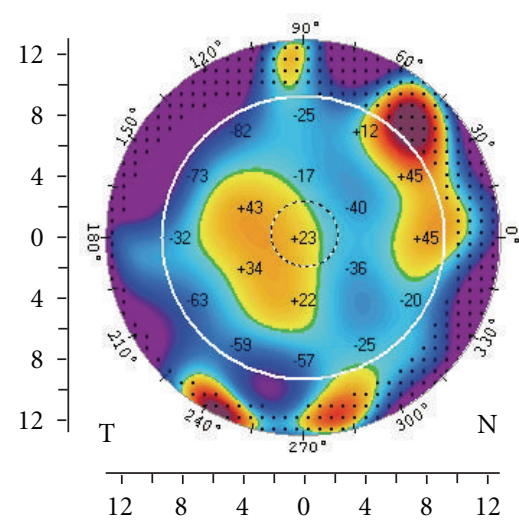

(c)

Figure 2: Pentacam corneal topography before (a), 7 months after (b), and 1 year after femtosecond laser-assisted LASIK (c). Note the relatively stable topography postoperatively and the substantially unchanged anterior and posterior elevation maps.

\section{References}

[1] M. O. Price and F. W. Price Jr., "Descemet's stripping with endothelial keratoplasty: comparative outcomes with microkeratome-dissected and manually dissected donor tissue," Ophthalmology, vol. 113, no. 11, pp. 1936-1942, 2006.

[2] S. B. Koenig, D. J. Covert, W. J. Dupps Jr., and D. M. Meisler, "Visual acuity, refractive error, and endothelial cell density six months after Descemet stripping and automated endothelial keratoplasty (DSAEK)," Cornea, vol. 26, no. 6, pp. 670-674, 2007.

[3] S. K. Rao, C. K. S. Leung, C. Y. L. Cheung et al., "Descemet stripping endothelial keratoplasty: effect of the surgical procedure on corneal optics," American Journal of Ophthalmology, vol. 145, no. 6, pp. 991-996, 2008.

[4] J. Kuryan and P. Channa, "Refractive surgery after corneal transplant," Current Opinion in Ophthalmology, vol. 21, no. 4, pp. 259-264, 2010. 
[5] I. S. Barequet, A. Hirsh, and S. Levinger, "Femtosecond thinflap LASIK for the correction of ametropia after penetrating keratoplasty," Journal of Refractive Surgery, vol. 26, no. 3, pp. 191-196, 2010.

[6] D. R. Hardten, A. Chittcharus, and R. L. Lindstrom, "Long term analysis of LASIK for the correction of refractive errors after penetrating keratoplasty," Cornea, vol. 23, no. 5, pp. 479489, 2004.

[7] E. Levinger, I. Bahar, and D. S. Rootman, "Intralase-enabled astigmatic keratotomy for correction of astigmatism after Descemet stripping automated endothelial keratoplasty: a case report," Cornea, vol. 28, no. 9, pp. 1074-1076, 2009.

[8] A. Ratanasit and M. Gorovoy, "Laser-assisted in situ keratomeileusis or photorefractive keratectomy after descemet stripping automated endothelial keratoplasy," Cornea, vol. 30, no. 7, pp. 787-789, 2011.

[9] G. M. Kezirian and K. G. Stonecipher, "Comparison of the IntraLase femtosecond laser and mechanical keratomes for laser in situ keratomileusis," Journal of Cataract and Refractive Surgery, vol. 30, no. 4, pp. 804-811, 2004.

[10] G. Muñoz, C. Albarrán-Diego, H. F. Sakla, T. Ferrer-Blasco, and J. Javaloy, "Effects of LASIK on corneal endothelium using the $15-\mathrm{kHz}$ IntraLase femtosecond laser," Journal of Refractive Surgery, vol. 27, no. 9, pp. 672-677, 2011. 


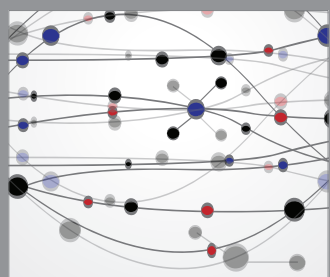

The Scientific World Journal
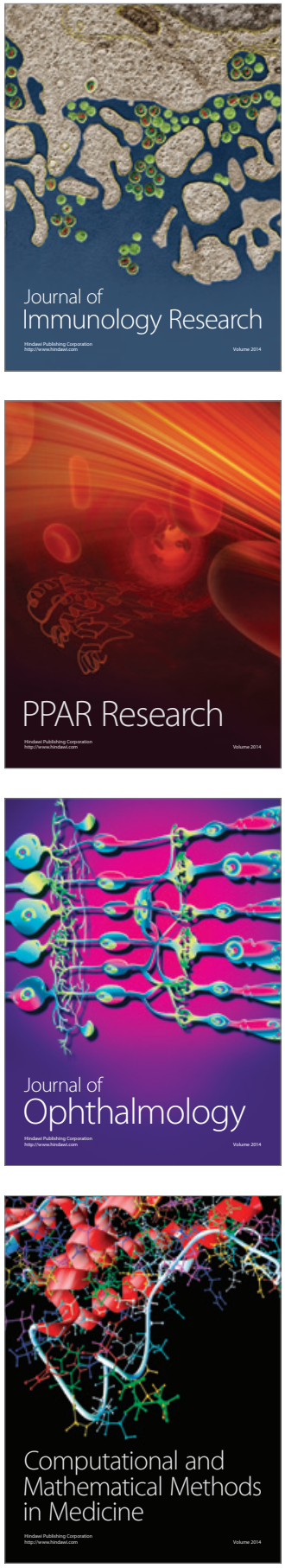

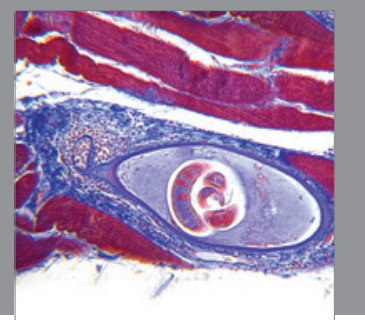

Gastroenterology

Research and Practice
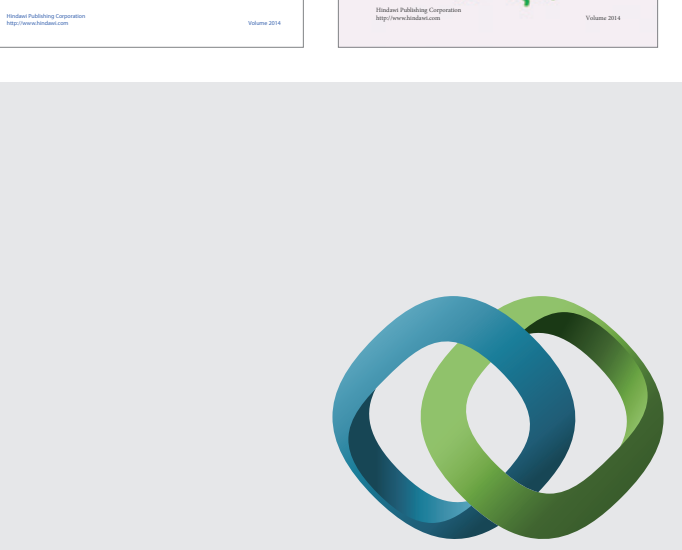

\section{Hindawi}

Submit your manuscripts at

http://www.hindawi.com
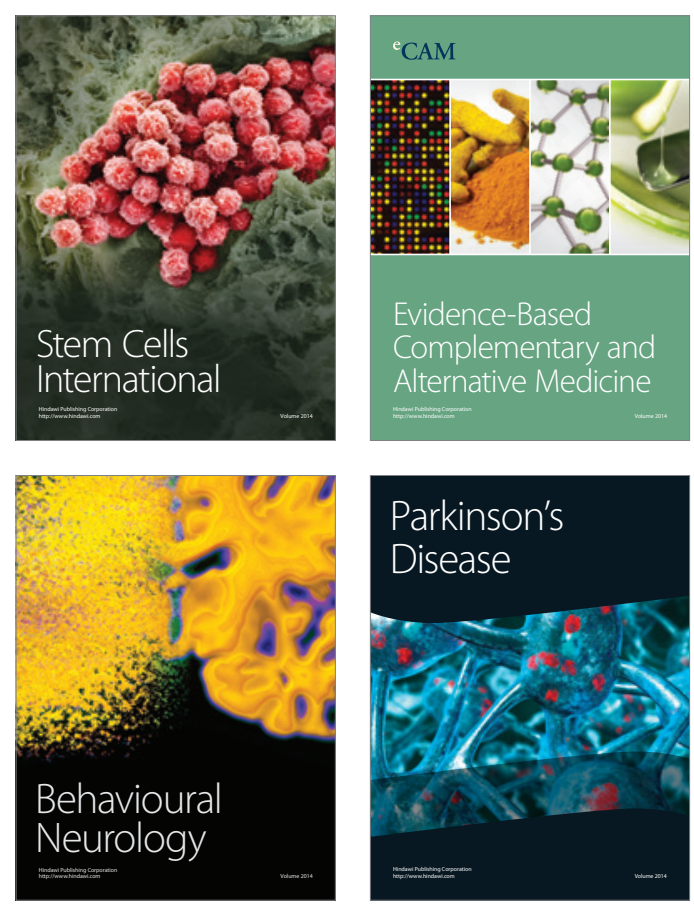

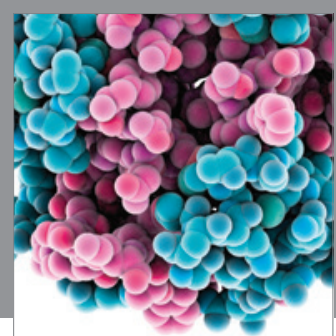

Journal of
Diabetes Research

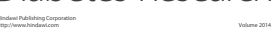

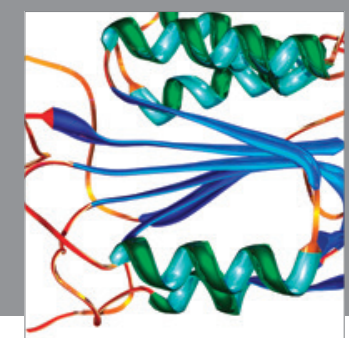

Disease Markers
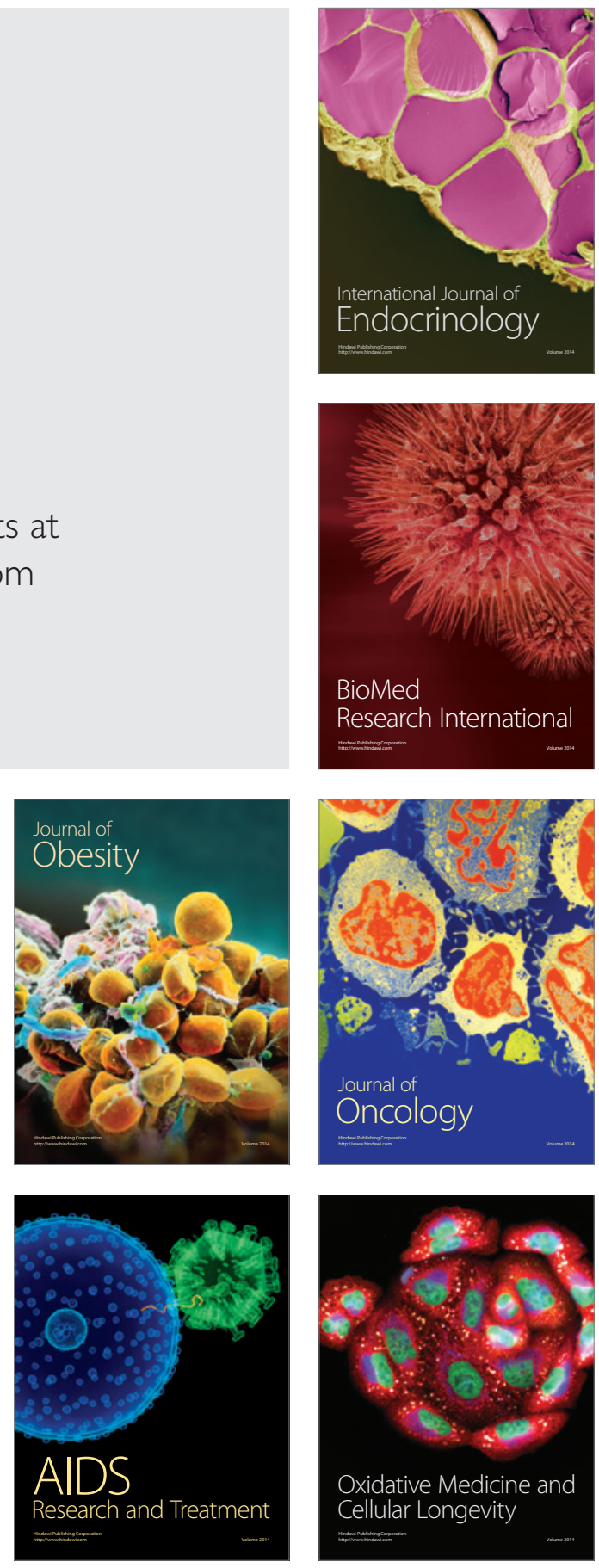